\title{
Tolerance to air exposure of the New Zealand mudsnail Potamopyrgus antipodarum (Hydrobiidae, Mollusca) as a prerequisite to survival in overland translocations
}

\author{
Álvaro Alonso', Pilar Castro-Díez' \\ I Departamento de Ecología, Facultad de Ciencias, Universidad de Alcalá, 28871 Alcalá de Henares, \\ Madrid, Spain \\ Corresponding author: Álvaro Alonso (aafernandez1976@yahoo.es) \\ Academic editor: S. Gollasch| Received 29 March 2012 | Accepted 28 May 2012 | Published 20 August 2012 \\ Citation: Alonso A, Castro-Díez P (2012) Tolerance to air exposure of the New Zealand mudsnail Potamopyrgus \\ antipodarum (Hydrobiidae, Mollusca) as a prerequisite to survival in overland translocations. NeoBiota 14: 67-74. doi: \\ $10.3897 /$ neobiota. 14.3140
}

\begin{abstract}
Spreading throughout a new ecosystem is the last step of an exotic species to become invasive. In the case of invasive aquatic molluscs, tolerance to air exposure is one of the main mechanisms allowing overland translocation and spreading. The mudsnail Potamopyrgus antipodarum (Hydrobiidae, Mollusca) is native to New Zealand but it has spread worldwide, invading ecosystems in Europe, Australia, America and Asia. The aim of our study is to assess mudsnail tolerance to air exposure, which may contribute to the successful overland translocation of this species. We conducted a laboratory experiment with four levels of air exposure $(9,18$, 24 and 36 hours in a controlled climatic chamber). Snails were placed for 60 seconds in a laboratory paper filter to remove surface snail water. Then they were placed back in empty vessels during the four periods of air exposure, except the control group, which was immediately returned to water. At the end of each period of air exposure all vessels were filled with water and the cumulative mortality was monitored after 24, 96, 168 and 264 hours of rehydration. The calculated Lethal Times (i.e. the time of air exposure (in hours) necessary to cause the death of 50\% (LT50) or 99\% (LT99) of the population) and their $95 \%$ confidence limits at 24, 96, 168 and 264 hours were 28.1 (25.2-31.9), 26.9 (24.2-30.1), 25.9 (23.4-28.9) and 25.9 (23.4-28.9) hours, respectively for LT50, and 49.6 (42.7-63.3), $45.6(39.9-56.5), 43.2(38.0-53.0)$ and 43.2 (38.0-53.0) hours, respectively for LT99. Therefore an air exposure time over 43 hours caused the death of all studied individuals during all monitoring periods. Extending the monitoring period beyond 24 hours did not significantly change lethal times. Therefore, we recommend exposing fishing tools or boats at open air during at least 53 hours as a low cost measure to control mudsnail spread in early stages of invasion.
\end{abstract}

\section{Keywords}

Exotic species, aquatic ecosystem, mudsnail, desiccation, spread

Copyright Álvaro Alonso, Pilar Castro-Díez. This is an open access article distributed under the terms of the Creative Commons Attribution License 3.0 (CC-BY), which permits unrestricted use, distribution, and reproduction in any medium, provided the original author and source are credited. 


\section{Introduction}

Biological invasions are one of the most important ecological problems at worldwide scale (Everett 2000). Humans have overcome all biogeographical barriers, connecting all parts of the World (Everett 2000, Nentwing 2007). This fact has facilitated the spread of exotic species on a large scale, causing a decline of biodiversity, a biotic homogenization of ecosystems (Enserink 1999, Gherardi 2007, Nentwing 2007), and huge economic costs (Everett 2000). The process of becoming an invasive species (i.e. an widespread exotic species that causes adverse effects on the invaded ecosystem) (Davis and Thompson 2000; Mack et al. 2000) is very complex and it is governed by an interaction of habitat conditions (e.g., climate), species functional traits (e.g., tolerance to environmental factors) and human factors (e.g., uses of the species) (Kolar and Lodge 2001, Gherardi 2007, Nentwing 2007, Castro-Díez et al. 2011). The invasion process includes three main steps: transport, establishment and spread (Kolar and Lodge 2001, Sakai et al. 2001). Exotic species must overcome all these steps through a combination of several mechanisms. Therefore only a small proportion of the exotic species arriving in a new ecosystem becomes invasive (Williamson and Fitter 1996, Sakai et al. 2001).

A rapid spread is the previous step to consider an exotic species as invasive. In the case of aquatic molluscs, tolerance to air exposure (i.e., absence of contact with water during a period of time) is one of the main prerequisites allowing overland transport, because many vectors require the ability to survive out of water (e.g., attached to nets, boats, buoys, waterfowl, etc.) (Ricciardi et al. 1995, Richards et al. 2004). Therefore the longer the period the mollusc can survive out of water the higher is the probability of successful translocation.

The mudsnail Potamopyrgus antipodarum (Hydrobiidae, Mollusca) is native to New Zealand but has spread worldwide, invading ecosystems in Europe, Australia, America and Asia (Alonso and Castro-Díez 2008). This snail is called mudsnail since it buries itself in the sediment during drought or cold periods (Duft et al. 2003a). This mollusc has a solid and well-formed operculum, a small narrow shell (length 1-10 mm), and it possesses a strong mobile and retractile foot (Winterbourn 1970, Kabat and Hershler 1993, Duft et al. 2003a, b). Non-native populations are parthenogenetic with almost all individuals being females, which allows a rapid colonization of the invaded ecosystems (Alonso and Castro-Díez 2008). Additionally, the potential number of generations per year is up to six, and the average number of offspring per adult is 230 (Møller et al. 1994, Richards 2002). This species can spread through transport vectors, such as fish, waterfowl or fishing tools, due to its ability to survive the passage through the digestive tract (in the case of fish) or to its air exposure tolerance (in the case of waterfowl or fishing tools) (Richards et al. 2004, Alonso and Castro-Díez 2008, Vinson and Baker 2008). The distance covered by means of the latter mechanism depends on how much time the mudsnail can survive out of water, which has not received much attention so far (but see Richards et al. 2004, Lysne and Koetsier 2006). Additionally, the knowledge of the air exposure tolerance can help to establish protocols to avoid translocation, as air exposure is a simple and low-cost method for exotic species 
control (Richards et al. 2004). This knowledge is crucial to avoid the establishment of mudsnail in new aquatic ecosystems (Richards et al. 2004) as the air-exposed vectors (e.g. birds, wild animals, human vectors, etc.) can be used by mudsnail to invade new aquatic ecosystems or to spread in an invaded ecosystem.

Previous studies on aquatic invasive molluscs have shown contrasting tolerances to air exposure among different species and environmental conditions. In the case of the mudsnail there are two studies for American populations (Richards et al. 2004, Lysne and Koetsier 2006). Both studies showed higher tolerance in bigger individuals and longer survival in damp and moist environments than in dry ones. However, no information is available on the air exposure tolerance of European populations of mudsnail which could possess contrasting tolerances. The aim of this study is the assessment of the air exposure tolerance of mudsnail under laboratory conditions to different periods of water absence to make recommendations to control the spread of this exotic species.

\section{Material and methods}

The snails used in the experiment (mean length size of $3.8 \mathrm{~mm}$, total number of 120) were obtained from our laboratory culture at the Department of Ecology (University of Alcalá). The culture was initiated with snails collected from the natural unpolluted upper reach of the Henares River (Guadalajara, Spain) in January 2009. Snails were kept in 60L glass aquaria with USEPA moderately hard water $(96 \mathrm{mg} \mathrm{NaHCO}, 60$ $\mathrm{mg} \mathrm{CaSO}{ }_{4}^{*} 2 \mathrm{H}_{2} \mathrm{O}, 4 \mathrm{mg} \mathrm{KCl}, 122.2 \mathrm{mg} \mathrm{MgSO}_{4} * 7 \mathrm{H}_{2} \mathrm{O}$ per litre of deionised water) (US Environmental Protection Agency 2002), enriched with calcium carbonate (10 mg $\mathrm{CaCO}_{3}$ per litre of deionised water). The culture was kept at room temperature $\left(20-22^{\circ} \mathrm{C}\right.$ ) with natural photoperiod (minimum daylight $=9 \mathrm{~h}$ and maximum daylight $=15 \mathrm{~h}$ ). Stock snails were fed with fish food (Tetra@ GmbH, Germany) and dry Spirulina (Sera@ Spirulina Tabs). The dry food per individual and day was around $0.10 \mathrm{mg}$. The culture was aerated with an air pump and an aquarium filter. Under these conditions snails reproduce and grow.

Snails for the experiment were obtained from the culture and acclimatized to the experimental conditions $\left(15^{\circ} \mathrm{C}\right.$ air temperature) in a controlled climatic chamber (Ansonic VSC3207). Experimental water was the same as that in the culture aquaria. Snails were acclimatized over seven days before the experiment. During this period snails were normally fed. This temperature was selected as the average for spring conditions, as higher temperatures decrease their survival (Richards et al. 2004).

An air exposure experiment was conducted, using four different periods $(0,9,18$, 24 and 36 hours without water in a controlled climatic chamber), each in triplicate. Eight adult snails were used in each replicate (120 individuals altogether), which consisted of a glass vessel of $8 \mathrm{~cm}$ diameter and $6 \mathrm{~cm}$ height. Snails of each replicate and air exposure treatment were taken with forceps and placed for 60 seconds on a laboratory paper filter (Anoia Filter, $73 \mathrm{~g} / \mathrm{m}^{2}$ ), rolling them over the paper until no surface water 
was visible on their surface (i.e., snail shell without shine). After this preliminary dehydration, snails were placed in empty vessels for 9, 18, 24 or 36 hours, depending on the assigned treatment. Three additional replicates (with 8 snails each) were returned to the water as control treatment ( 0 hours of air exposure with preliminary dehydration). At the end of each air exposure period, vessels from each treatment were filled with control water (US-EPA water) and the cumulative mortality was monitored after 24, 96, 168 and 264 hours of hydration, including control treatment. Mortality was assessed by observing each snail under a binocular. An animal with a closed operculum was considered immobile and alive if after touching the operculum with forceps the snail retracted its soft body. If not it was considered dead. During the experiment air temperature and humidity in the climatic chamber were measured using a digital thermometer-hydrometer.

The lethal time 50 (LT50) and 99 (LT99) (i.e., the time of air exposure in hours that caused the death of $50 \%$ and $99 \%$ of the studied population, respectively) after 24, 96, 168 and 264 hours since the end of air exposure, and their respective 95\% confidence limits were calculated using probit regression analysis (Finney 1971). The dependent variable was the probit transformation of the proportion of dead snails responding to each air exposure period (9, 18, 24 and 36 hours without water), and the independent variable was the air exposure period. Statistical analyses were conducted with SPSS 15.0 software. LT values were compared between different monitoring times using the confidence interval overlap test (Wheeler et al. 2006)

\section{Results}

The mean $\pm \mathrm{SD}(\mathrm{n}=10)$ environmental conditions during the experiments were $68.9 \pm 6.6$ $\%$ of relative air humidity and $15.4 \pm 0.5^{\circ} \mathrm{C}$ of air temperature. The mortality of $P$. antipodarum was relatively low up to 20 hours of air exposure. After this time, mortality increased (Fig. 1). Air exposure times between 25.9 and 28.1 (LT50), and between 43.2 and 49.6 hours (LT99) caused the death of the half and all studied population, respectively (Table 1). An increase of the monitoring time neither changed LT50 nor LT99 values, as the confidence limits between different monitoring times overlapped (Confidence interval overlap test; $p>0.05$ ). Therefore, an air exposure treatment of 53 hours (upper limit of LT99 at 264 hours) assured the death of all snails.

Table I. LT50 and LT99 values (in hours) at 24, 96, 168 and 264 hours for each time of mortality monitoring. $95 \%$ confidence limits are presented in parentheses.

\begin{tabular}{c|c|c|c|c}
\hline & $\mathbf{2 4} \mathbf{~ h}$ & $\mathbf{9 6} \mathbf{~}$ & $\mathbf{1 6 8} \mathbf{~}$ & $\mathbf{2 6 4} \mathbf{~}$ \\
\hline \multirow{2}{*}{ LT50 (in hours) } & 28.1 & 26.9 & 25.9 & 25.9 \\
& $(25.2-31.9)$ & $(24.2-30.1)$ & $(23.4-28.9)$ & $(23.4-28.9)$ \\
\hline \multirow{2}{*}{ LT99 (in hours) } & 49.6 & 45.6 & 43.2 & 43.2 \\
& $(42.7-63.3)$ & $(39.9-56.5)$ & $(38.0-53.0)$ & $(38.0-53.0)$ \\
\hline
\end{tabular}




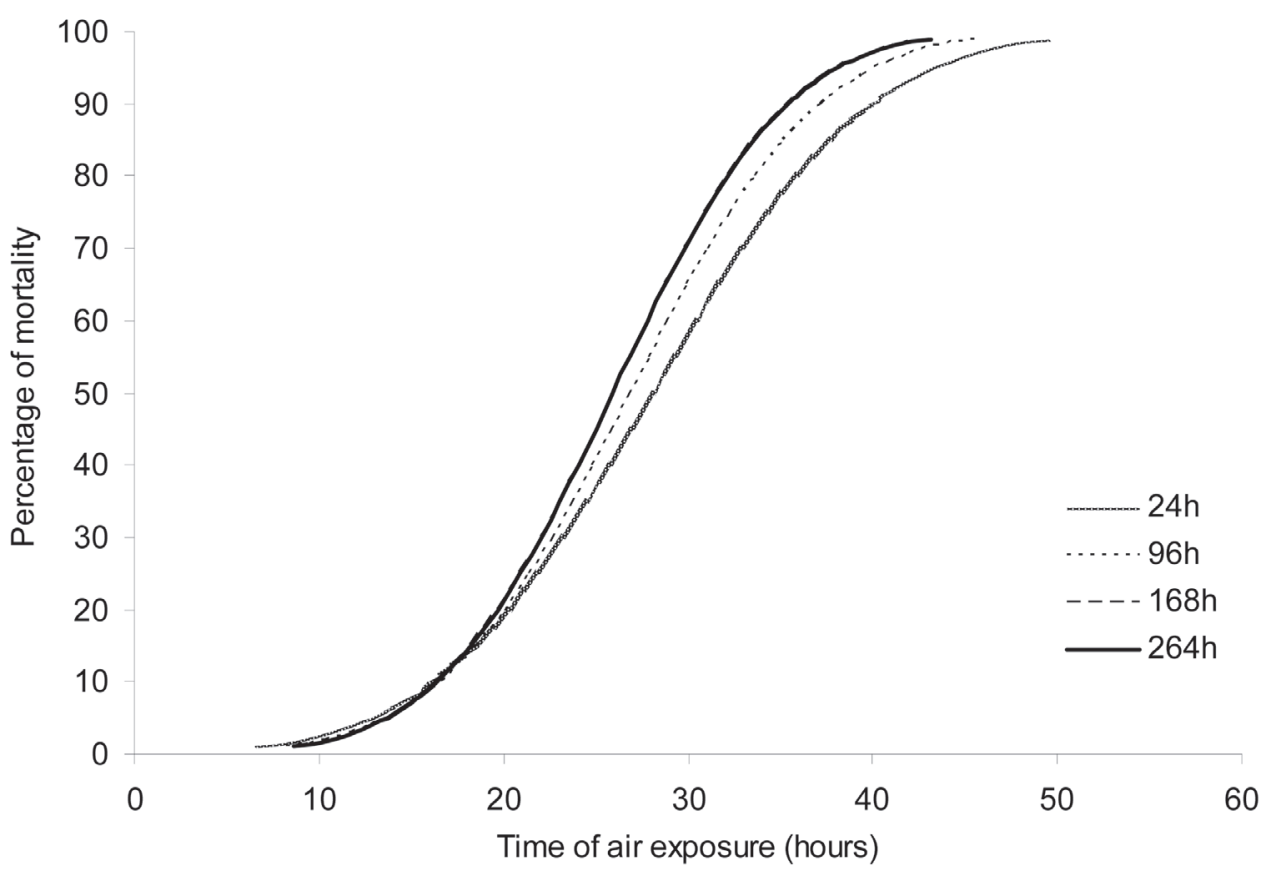

Figure I. Modelled probit curves for the percentage of mortality of Potamopyrgus antipodarum for each time of monitoring after returning the animals to water. Curves at 168 hours and 264 hours fully overlaped.

\section{Discussion}

Our study demonstrated that survival of air-exposed mudsnail over short-period transport $(<24 \mathrm{~h})$ through non-aquatic media is highly probable. This scenario could be accomplished in waterfowl movements, transport of fishing tools (rubber boots, boats, nets, etc.) or movement of terrestrial animals (sheep, cows, domestic dogs, deer, etc.). Therefore the desiccation tolerance may be one of the most important traits promoting the traslocation of mudsnail in inland waters. In an American population Richards et al. (2004) found a very similar tolerance of mudsnail to air exposure, with a 99\% lethal time of 50 hours for individuals with shell size and environmental conditions similar to those in our study. Additionally, these authors found that under favourable conditions (temperature $9^{\circ} \mathrm{C}$ ) $99 \%$ of the population died after 60 hours, and that small individuals were less tolerant than adults. This result is in the range of the upper LT99 confidence limit found in our study. Our study was conducted under relatively high humidity (mean $\mathrm{RH}$ of $69 \%$ ) and $15^{\circ} \mathrm{C}$ of temperature which represent favourable conditions to tolerate air exposure in molluscs (Byrne et al. 1988, Alli and Nakamura 1999, Richards et al. 2004). Therefore, unfavourable conditions (high temperature, dry summer, low humidity during transport, etc.) would shorten this LT99. In fact, other studies with molluscs have shown that air exposure under lower relative humidity and/or higher temperature cause mortality in shorter times (Byrne et al. 1988, Ali and Nakamura 1999, Richards et al. 2004, Havel 2011). Additionally, most of these studies showed that smaller snails 
were more sensitive to air exposure that larger snails. Therefore our recommended air exposure of 53 hours, calculated for large individuals and favourable conditions, could be time enough to ensure no survival of mudsnail in non-water translocation. Beside, large snails (the most prone to tolerate air transport) are the easiest to locate and remove from macrophytes, boat surface or waders. Other transportation vectors, such as domestic animals and waterfowl are risky vectors as the time to reach a new water body can be relatively short.

Air exposure caused several harmful effects in aquatic animals. In the case of mollusc a rapid loss of body water has been observed, being faster in small individuals than in large individuals (Ricciardi et al. 1995). However, other physiological effects of air exposure have been reported for molluscs, such as depletion of energy reserves, acidosis and accumulation of anaerobic metabolites (Byrne et al. 1990). Therefore, one of those effects (or a combination of them) can cause the mortality observed in our experiment.

The hard operculum of New Zealand mudsnail can contribute to explain its high tolerance to air exposure. In a previous study, Wood et al. (2011) showed that adults of the native non operculated gastropod Physa gyrina presented a lower tolerance to air exposure than the operculated invasive snail Bithynia tentaculata. The hard carbonate operculum of mudsnail is a good barrier to avoid water loss, which can prolong the tolerance to air exposure, as shown for similar species (Wood et al. 2011).

\section{Conclusions}

Avoiding the spread of invasive species is crucial for the conservation of aquatic native biodiversity. The results of our study suggest several low-cost measures to decrease the spread of mudsnail among reaches and aquatic ecosystems. First we recommend a desiccation treatment to all tools or instruments that are going to be repeatedly used in different aquatic ecosystems (e.g., exposing fishing tools at air during at least 50 hours, preferably at full sun light). Second, we recommend avoiding the access of wild and domestic animals to infected reaches or lakes (e.g., by using physical barriers or scarecrows for waterfowl). These simple measures may reduce mudsnail translocations in early stages of invasion.

\section{Acknowledgements}

This research was funded by the Spanish Ministry of Science and Innovation (SMSI) (CGL2010-16388/BOS) and by the Castilla-La Mancha Community (POII10-0179470). The University of Alcalá provided logistical support. Dr. Álvaro Alonso was supported by a Juan de la Cierva contract from the SMSI at University of Alcalá. Many thanks to Enrique González for his help during the experiment. Especial thanks to Dr. Julio A. Camargo for providing climatic chamber for experiment. 


\section{References}

Ali F, Nakamura K (1999) Effect of temperature and relative humidity on the tolerance of the Japanese clam, Ruditapes philippinarum (Adams \& Reeve), to air exposure. Aquaculture Research 30: 629-636. doi: 10.1046/j.1365-2109.1999.00303.x

Alonso A, Castro-Díez P (2008) What explains the invading success of the aquatic mud snail Potamopyrgus antipodarum (Hydrobiidae, Mollusca)? Hydrobiologia 614: 107-116. doi: 10.1007/s10750-008-9529-3

Byrne RA, Mcmahon RF, Dietz TH (1988) Temperature and relative humidity effects on aerial exposure tolerance in the freshwater bivalve Corbicula fluminea. Biological Bulletin 175: 253-260. doi: 10.2307/1541566

Byrne RA, Gnaiger E, McMahon RF, Dietz TH (1990) Behavioural and metabolic responses to emersion and subsequent reimmersion in the freshwater bivalve, Corbicula fluminea. Biological Bulletin 178: 251-259. doi: 10.2307/1541826

Castro-Díez P, Godoy O, Saldaña A, Richardson DM (2011) Predicting invasiveness of Australian acacias on the basis of their native climatic affinities, life history traits and human use. Diversity and Distributions 17: 934-945. doi: 10.1111/j.1472-4642.2011.00778.x

Davis MA, Thompson K (2000) Eight ways to be a colonizer; two ways to be an invader: a proposed nomenclature scheme for invasion ecology. ESA Bulletin 81: 226-230.

Duft M, Schulte-Oehlmann U, Tillman M, Markert B, Oehlmann J (2003a) Toxicity of triphenyltin and tributyltin to the freshwater mudsnail Potamopyrgus antipodarum in a new sediment biotest. Environmental Toxicology and Chemistry 22: 145-152. doi: 10.1002/ etc. 5620220119

Duft M, Schulte-Oehlmann U, Weltje L, Tillmann M, Oehlmann J (2003b) Stimulated embryo production as a parameter of estrogenic exposure via sediments in the freshwater mudsnail Potamopyrgus antipodarum. Aquatic Toxicology 64: 437-449. doi: 10.1016/ S0166-445X(03)00102-4

Enserink M (1999) Biological invaders sweep in. Science 285: 1834-1836. doi: 10.1126/science.285.5435.1834

Everett RA (2000) Patterns and pathways of biological invasions. Trends in Ecology and Evolution 15:177-178. doi: 10.1016/S0169-5347(00)01835-8

Finney DJ (1971) Probit Analysis. Cambridge University Press.

Gherardi F (2007) Biological Invaders in Inland Waters: Profiles, Distribution, and threats. Springer, The Netherlands. doi: 10.1007/978-1-4020-6029-8

Havel JE (2011) Survival of the exotic Chinese mystery snail (Cipangopaludina chinensis malleata) during air exposure and implications for overland dispersal by boats. Hydrobiologia 668: 195-202. doi: 10.1007/s10750-010-0566-3

Kabat AR, Hershler R (1993) The Prosobranch Snail Family Hydrobiidae (Gastropoda: Rissooidea): Review of Classification and Supraspecific Taxa. Smithsonian Contributions to Zoology, number 547, $94 \mathrm{pp}$.

Kolar CS, Lodge DM (2001) Progress in invasion biology: predicting invaders. Trends in Ecology and Evolution 16: 199-204. doi: 10.1016/S0169-5347(01)02101-2 
Lysne S, Koetsier P (2006) Experimental studies on habitat preference and tolerances of three species of snails from the Snake River of southern Idaho, USA. American Malacological Bulletin 21: 77-85.

Mack RN, Simberloff D, Lonsdale WM, Evans H, Clout M, Bazzaz FA (2000) Biotic invasions: causes, epidemiology, global consequences and control. Ecological Applications 10: 689-710. doi: 10.1890/1051-0761(2000)010[0689:BICEGC]2.0.CO;2

Møller V, Forbes VE, Depledge MH (1994) Influence of acclimation and exposure temperature on the acute toxicity of cadmium to the freshwater snail Potamopyrgus antipodarum (Hydrobiidae). Environmental Toxicology and Chemistry 13: 1519-1524. doi: 10.1002/ etc. 5620130914

Nentwing W (2007) Biological invasions: why it matters. In: Nentwing W (Ed) Biological Invasions. Ecological Studies Vol 193: 1-6.

Ricciardi A, Serrouya R, Whoriskey FG (1995) Aerial exposure tolerance of zebra and quagga mussels (Bivalvia: Dreissenidae): implications for overland dispersal. Canadian Journal of Fisheries and Aquatic Sciences 52: 470-477. doi: 10.1139/f95-048

Richards DC (2002) The New Zealand mudsnail invades the Western United States. Aquatic Nuisance Species 4: 42-44.

Richards DC, O'Connell P, Shinn DC (2004) Simple control method to limit the spread of the New Zealand mudsnail Potamopyrgus antipodarum. North American Journal of Fisheries Management 24: 114-117. doi: 10.1577/M02-133

Sakai AK, Allendorf FW, Holt JS, Lodge DM, Molofsky J, With KA, Baughman S, Cabin RJ, Cohen JE, Ellstrand NC, McCauley DE, O’Neil P, Parker IM, Thompson JN, Weller SG (2001) The population biology of invasive species. Annual Review of Ecology and Systematics 32: 305-332. doi: 10.1146/annurev.ecolsys.32.081501.114037

U.S. Environmental Protection Agency (2002) Short-term methods for estimating the chronic toxicity of effluents and receiving waters to freshwater organisms. Environmental Protection Agency, 821-R-02-013. Fourth ed., Washington, DC.

Vinson MR, Baker MA (2008) Poor growth of rainbow trout fed New Zealand mud snails Potamopyrgus antipodarum. North American Journal of Fisheries Management 28: 701-709. doi: 10.1577/M06-039.1

Wheeler MW, Park RM, Bailer AJ (2006) Comparing median lethal concentration values using confidence interval overlap or ratio test. Environmental Toxicology and Chemistry 25: 1441-1444 doi: 10.1897/05-320R.1

Williamson M, Fitter A (1996) The varying success of invaders. Ecology 77: 1661-1666. doi: $10.2307 / 2265769$

Winterbourn MJ (1970) The New Zealand species of Potamopyrgus (Gastropoda: Hydrobiidae). Malacologia 10: 283-321.

Wood AM, Haro CR, Haro RJ, Sandland GJ (2011) Effects of desiccation on two life stages of an invasive snail and its native cohabitant. Hydrobiologia 675: 167-174. doi: 10.1007/ s10750-011-0814-1 